\title{
Is Technology Paving the Way for Autonomous Learning?
}

\author{
Mehran Esfandiari ${ }^{1} \&$ Mir Wais Gawhary ${ }^{1}$ \\ ${ }^{1}$ Defense Language Institute Foreign Language Center, Monterey, California, The United States of America \\ Correspondence: Mehran Esfandiari, Defense Language Institute Foreign Language Center, Monterey, California, \\ The United States of America.
}

Received: August 5, 2019

Accepted: August 20, 2019 Online Published: August 27, 2019

doi:10.5430/wjel.v9n2p64

URL: https://doi.org/10.5430/wjel.v9n2p64

\begin{abstract}
The shift towards communicative, learner-centered approaches to teaching has resulted in attention being drawn to promoting autonomy as a capacity for independent learning. Taking responsibility for their own learning enables students to break down barriers to learning that appear in teacher-directed environments. With independence and interdependence as its two interrelated aspects, autonomy has its roots in interaction with others in social contexts, and it is now looked upon as being certain abilities that facilitate the navigation of learning through higher degrees of motivation, creative thinking, and conceptual learning. Thanks to technology, language learners easily access authentic materials for out-of-class learning. However, this paper aims to argue that where promoting autonomous learning is concerned, it cannot be enough per se; proper guidance is crucial, and the interrelation between pedagogy and technology has to be explored so that enough attention is paid to the affordances of certain technological tools to enable language learners to become more autonomous.
\end{abstract}

Keywords: autonomy, learner training, autonomous learners, motivation

\section{Introduction}

Following the shift from traditional towards more learner-centered approaches to teaching English, the concept of learner autonomy has been the subject of heated debate in the field of language education. In teacher-directed environments, where the teacher takes charge of the transmission of knowledge to the class and learners are taken to be information containers with limited chances of using functional language, autonomy is often regarded as something akin to the abolition of the teaching profession resulting in educational anarchy. However, a variety of reasons have been proposed in justification of the promotion of greater learner autonomy in language learning.

When learners take more responsibility for their own learning, they will be better able to break down barriers to learning that normally arise in traditional teacher-directed approaches. This can then lead to higher degrees of enthusiasm for learning (Holec, 1981; Little, 1991). Indeed, independence and interdependence are considered the two interrelated aspects of autonomy which has its roots in interaction with others in social contexts. Furthermore, autonomy and motivation are also closely linked to each other through such concepts as learner independence, responsibility, and choice. Since autonomous learners are in charge of their own learning, they benefit from a high level of motivation and therefore learn more efficiently through conceptual learning and creative thinking. Thus, autonomy is now undergoing a shift towards certain abilities that make the navigation of different learning environments easier.

As a source of information in this day and age, technology can play a major role in such a shift. Thanks to the Internet, students are provided with the opportunity to have unlimited access to authentic materials in the target language. This enables them to access a wide range of resources for out-of-class learning. The main aim of this paper is to argue that although technology seems to have the potential to create opportunities for the promotion of autonomous learning, it cannot be enough per se as proper guidance seems to be crucial. Therefore, it is important to explore the interrelation between pedagogy and technology so that enough attention is paid to the affordances of certain technological tools to enable learners to become more autonomous in their language learning.

\section{What Is Autonomy?}

Although the term autonomy in its broadest sense refers to independence from external hierarchies, it is not a straightforward task to set out what it means, as multiple layers of meaning can be uncovered. From a historical viewpoint, the origins can be traced back to the ancient political system of the Greek states where it was looked upon 
as not only political self-government for communities, but also as personal freedom for individuals (Vestheim, 2007). Therefore, as a social and individual construct, autonomy would mean the freedom to make one's own laws and informed decisions independently.

During the $17^{\text {th }}$ century, in order to become independent of religious power, the concept of autonomy was introduced to secular scientific and political philosophy (Vestheim, 2009). Philosophers related the concept of autonomy to that of self-sufficiency. They laid great emphasis on the key role that obedience would play in law and freedom which were believed to be the two sides of the same coin. However, it can be argued that freedom is not the same as autonomy. For one thing, complete autonomy is always constrained by socio-cultural and ideological limitations of a context. For another, autonomy is more complex than simply freedom, and it requires certain attributes on the part of the agent. In order for an individual to be capable of acting autonomously, three factors are of paramount importance. These are "appropriate mental abilities, an adequate range of options, and independence" (Raz, 1986, p. 372). Thus, autonomy is not simply independence, as a person "can be autonomous only if he believes that he has valuable options to choose from" (Raz 1986, p. 412). On the other hand, autonomy is argued to be a kind of positive ability to live one's own life in a way that is not totally dictated by the set of dominant values of a society (Brenkert, 1991). Indeed, it occurs when people have more control over their own lives either individually or collectively (Benson, 2006).

In the eyes of psychologists, autonomy is a capacity to take action with no external intervention. As far as cognitive psychology is concerned, the constructivist approach deals with autonomy as mental processes of individuals for bringing a sense of personal meaning to their world (Williams \& Burden, 1997). Unlike cognitive psychology, socio-cultural psychology highlights interaction with others as the social aspect of autonomy (Benson, 2001). In addition, there is humanistic psychology with its strong focus on learning environments that can pave the way for certain conditions to "overcome the threatening affective factors" (Brown 2000, p. 104). However, it is inevitable that grasping the complete notion of autonomy within just the aforementioned domains is not adequate for pedagogical purposes.

\section{What Is Learner Autonomy?}

With the shift towards more communicative and learner-centered approaches to teaching, a great deal of attention has been paid to learner autonomy from a variety of angles over the past few decades. From a semantic viewpoint, it has appeared to be such a complex term that providing its precise definition seems to be quite challenging. There is the assumption that philosophy and psychology have both played a major role in establishing the basis for autonomy in the context of education and language learning. Indeed, self-directed learning is often regarded as a synonym for learner autonomy, so much so that as an extreme form of autonomy, self-instruction is defined as "learning without the direct control of a teacher" (Dickinson, 1987, p. 5). However, it is argued that the whole learning process in the classroom cannot be feasibly handed over to learners and that teachers are not due to be made redundant (Little, 1991).

Perhaps the most oft-quoted definition of autonomy in Applied Linguistics literature can be attributed to Holec (1981) who defines it as "the ability to take charge of one's own learning...To take charge of one's learning is to have, and to hold, the responsibility for all the decisions concerning all aspects of this learning" (p. 3). Simply stated, it is the ability to learn actively and independently. Little (1991) highlights autonomy as "a capacity for detachment, critical reflection, decision making and independent action" (p. 4). That is to say, it is the ability to take responsibility for one's own learning. In the eyes of Dam (1995), "a learner qualifies as an autonomous learner when he independently chooses aims and purposes and sets goals; chooses materials, methods and tasks; exercises choice and purpose in organizing and carrying out the chosen tasks; and chooses criteria for evaluation" (p. 45).

Having defined autonomy as being able to take control of one's own learning, Holec (1981) points out that autonomous learners are able to make up their minds in connection with their learning. However, there have been criticisms of his rather stark definition. It is argued that it does not take into account "the nature of the cognitive capabilities underlying effective self-management of learning" (Benson, 2001, p. 49), so taking control is not as straightforward as such a definition may suggest. Instead, some form of teacher intervention seems to be necessary; the teacher's role in encouraging learner involvement, learner reflection, and appropriate target language use can be seen as pedagogical principles of encouraging autonomy in learning (Little \& Dam, 1989). Indeed, autonomous learners can work not only independently, but also confidently as the result of acquiring learning strategies and broadening their knowledge of learning through teacher intervention.

By adding a psychological aspect to Holec's definition, Little (1991) suggests that learners need to raise their awareness about what to learn and how to learn. However, it is again argued that this definition underestimates the Published by Sciedu Press 
fact that "autonomous learning presupposes freedom of learners to determine the content of learning" (Benson, 2001, p. 49) and that in many educational contexts such freedom is not feasible. Littlewood (1996), on the other hand, believes that autonomy is an ability that has to be acquired; and when it comes to promoting learner autonomy, interaction, negotiation, collaboration, and teacher support are crucial elements with the potential to pave the way for higher levels of motivation to learn autonomously.

Having considered the above ideas, Benson (1997) classifies autonomy into three major categories:

\section{Technical autonomy}

The technical aspect of learner autonomy, which mainly appears in discussions on learner strategy and learner training, is referred to as training in the strategies and techniques required for learning outside an educational organization without the intervention of a teacher. The primary concern of technical autonomy is to ensure that language learners are equipped with the necessary skills to manage their learning outside the classroom. Such a version of autonomy is related to positivism where drill-and-practice approaches to language learning are encouraged (Benson, 1997).

\section{Psychological autonomy}

The psychological aspect of autonomy is described as "an internal transformation within the individual" (Benson, 1997, p. 19) or learners' internal capacity to be in a position of responsibility for their own learning. It broadly agrees with ideas on self-directed and self-access language learning. Therefore, it is connected with constructivism which takes knowledge into consideration as the construction of meaning. Constructivism attaches significance to not only individual freedom in thinking and acting, but also to individual responsibility for decision making on learning (Halliday, 1975). Little (1991) divides psychological autonomy into three sub-categories as motivational, metacognitive, and affective dimensions. The motivational dimension concentrates on the cognitive psychological approach to motivation, while the metacognitive dimension is concerned with learners' awareness of metacognitive knowledge and reflection. He argues that reflection and deliberate intention play a crucial role in autonomous learning, as they enable learners to reflect on the process of learning and develop their own way of learning in light of their reflections. Last but not least, the affective dimension deals with various affective factors that can have a positive or even a negative impact on learning.

\section{Political autonomy}

Political autonomy is characterized by "control over the content and process of one's own learning" (Benson, 1997, p. 25). It lays great emphasis on language learners' rights to take control of not only what, but also how to learn. Furthermore, it considers issues of power that might exist between second language learners and the target language communities. Within such a version of autonomy, "authoring one's own world without being subject to the will of others" is taken into account as the basic idea (Young, 1986, p. 19). It is important to note that the political version of learner autonomy is supported by critical theory which relates language learning to the issues of power and control in critical pedagogies.

It is interesting to note that Benson (1997) aims to argue for the superiority of the political version and to dismiss the technical version as a reductive and inferior form of autonomy. However, a fourth aspect - known as social autonomy - should be added to the above classifications which itself can be divided into two sub-categories: social-interactive and cultural dimensions. As the name suggests, the main focus of the social interactive dimension is on the role that social interaction can play in promoting learner autonomy. In contrast, the cultural dimension draws attention to the culture of the context. Since "language cannot be isolated from the particular context in which it is used" (Pennycook, 1997, p. 47), it can be argued that autonomy results from the social structure of a particular society, so it cannot be culturally universal.

Interestingly, not only does Sinclair (2000) stress the importance of a broad and realistic description of learner autonomy that accommodates its different dimensions, but she also puts forward a framework that has been widely accepted by language teaching authorities, as it integrates the different strands of autonomy. She suggests thirteen aspects of autonomy as follows: "autonomy is a construct of capacity; autonomy involves a willingness on the part of the learner to take responsibility for their own learning; the capacity and willingness of learners to take such responsibility is not necessarily innate; complete autonomy is an idealistic goal; there are degrees of autonomy; the degrees of autonomy are unstable and variable; autonomy is not simply a matter of placing learners in situations where they have to be independent; developing autonomy requires conscious awareness of the learning process, i.e., conscious reflection and decision making; promoting autonomy is not simply a matter of teaching strategies; autonomy can take place both inside and outside the classroom; autonomy has a social as well as an individual 
dimension; the promotion of learner autonomy has a political as well as psychological dimension; autonomy is interpreted differently by different cultures" (p. 7-13).

\section{Why Foster Learner Autonomy?}

A great deal of emphasis has been placed on the promotion of learner autonomy in the literature. It is interesting to note that a significant number of justifications have been proposed for fostering learner autonomy. Where learning is concerned, it is believed to result in a higher level of enthusiasm (Littlejohn, 1985). Indeed, as a result of being proactively committed to their learning, autonomous learners may be able to succeed in dealing with temporary motivational issues. Therefore, it can facilitate effective learning, particularly where learners have difficulty gaining access to teachers' instruction (Cotteral, 1995). Moreover, "personal involvement in decision making leads to more effective learning" (Dickinson, 1995, p. 165). Thus, since learners are reflectively involved in their learning, a learning task can have a positive influence on the learning process when it is performed independently.

It should also be mentioned that the importance of educational contexts has to be emphasized as they can play a significant role in the process of learning. Whatever is learnt in such contexts may serve learners' broader agendas. If the main aim of a course is to foster learner autonomy, it "must incorporate frank discussions of objectives, methodology, roles, and expectations" (Cotteral , 1995, p. 224). This will enable learners to apply classroom tasks to their potential needs. However, it can be argued that a significant proportion of language learning that is undertaken by students may occur unassisted outside of the classroom walls. Thus, autonomy both inside and outside the classroom need to be considered.

\section{Why Foster Autonomy in Language Learning?}

With the shift towards more learner-centered approaches to language learning, a number of autonomy-related terms, such as the learner-centered curriculum (Nunan, 1988), learner training (Ellis \& Sinclair, 1989), learning-strategy training (Wenden, 1991), and experiential and collaborative learning (Nunan, 1992) have been introduced to the field of language education. It is interesting to note that a variety of reasons have been proposed in justification of learner autonomy in language learning. It leads to higher degrees of motivation (Littlejohn, 1985) plus when learners take responsibility for their own learning, they will be capable of breaking down barriers to learning that normally arise in traditional teacher-directed approaches (Little, 1991). When such barriers do not arise, learners might find it far easier to transfer their capacity for autonomous behavior to other aspects of their lives and become more effective participants. In addition, more progress can be made when personal involvement is encouraged in the decision-making process (Dickinson, 1995); as a result of having learners set the agenda, learning becomes more focused and purposeful. Indeed, "learners who achieve proficiency in foreign languages tend to take some degree of control over the overall direction of their learning" (Benson, 2001, p. 65). Considering the capability of communicating and learning independently as the key to success in making choices in everyday life, three main principal of autonomy can be highlighted: communication, learning, and personal life (Littlewood, 1996). Interestingly, where learning is concerned, it is important to note that learners have their own learning styles, so they devise their own systems of knowledge (Skehan, 1989; Oxford, 1990; Wenden, 1991; Willing, 1988).

It also needs to be emphasized that the essence of autonomy is that learners enjoy freedom of choice. However, such freedom is always constrained and never absolute (Sinclair, 1996). Dickinson (1987), Little (1991), and Nunan (1997) put forward the notion of degrees of autonomy. They argue that these are heavily dependent on a variety of factors ranging from the personality of learners and their ability to take responsibility to personal constructs, goals, teacher support, peer support, and flexibility in learning environments. Sinclair (2000), on the other hand, asserts that "degrees of autonomy fluctuate according to a wide range of variables, such as affective factors (e.g. mood), environment (e.g. noise, temperature), physiological factors (e.g. tiredness, hunger), motivation (e.g. attitude towards the task, the subject matter, the teacher, materials, co-learners) and so on" (p. 8). Furthermore, she argues that even where performing a similar task is concerned, various degrees of autonomy will be displayed by learners on different occasions.

To summarize, Kohonen (2001) proposes essential factors for developing autonomy in language learning as follows:

i. Being involved in the decision-making process of learning

ii. Having the right to make choices about the content of learning

iii. Reflecting on the results

iv. Becoming aware of achievements

v. Broadening knowledge of new needs

Published by Sciedu Press 
Summing up the discussion, for the development of learner autonomy in language learning, there is a need for consciousness of the learning process. Simply stated, it is crucial that learners become aware of what they have already achieved and further reflect on it. Therefore, particular attention needs to be drawn to learner strategies.

\section{Autonomous Learners and Learner Strategies}

Over the past few decades, learner autonomy has appeared to be a focal point. Autonomous learners are capable of not only setting the aims and objectives, but also devising strategies to achieve them as a particular end. They are also able to evaluate themselves in terms of fulfilling certain criteria. Indeed, an autonomous learner is the "one who has acquired the strategies and knowledge to take some (if not yet all) responsibility for her language learning and is willing and self-confident enough to do so" (Wenden, 1991, p. 163). That is to say, such learners take responsibility for their own learning by devising or selecting effective learning strategies, which are considered "specific actions taken by the learner to make learning easier, faster, more enjoyable, more self-directed, more effective, and more transferable to new situations" (Oxford, 1990, p. 8).

It is important to note that learning strategies fall into six broad categories. They are known as cognitive, meta-cognitive, memory-related, compensatory, affective, and social strategies. Cognitive strategies pave the way for direct manipulation of the language material (Oxford, 2003). It is argued that they "are more limited to specific learning tasks and involve more direct manipulation of the learning material itself" (Brown, 2000, p. 124). Meta-cognitive strategies, on the other hand, enable learners to "coordinate their own learning process" (Oxford, 1990 , p. 135). Simply stated, they help them to not only organize, but also to assess their learning. Where memory-related strategies are concerned, deep understanding is not necessarily involved. Such strategies assist learners to develop a link between language concepts. In contrast, compensatory strategies enable learners to compensate for missing knowledge. Finally, while affective strategies are mainly related to feelings and behaviors, social strategies help learners to not only learn the language, but also to develop a better understanding of the target culture as a result of interaction and learning with others (Oxford, 2003).

\section{Autonomous Learners and Control}

A great deal of effort has been made to draw attention to responsibility and control as the core aspects of learner autonomy. Based on the notion of control, autonomy presupposes the readiness of learners for having control over their own learning. Autonomous learners "initiate and manage their own learning, set their own priorities and agendas and attempt to control psychological factors that influence their learning" (Benson, 2001, p. 75). However, in order for learners to be considered autonomous, it is essential to take control of their learning systematically. Depending upon the level of the learning process, a distinction can be drawn between different forms of such control. Benson (2001) asserts that "any adequate description of autonomy in language learning should at least recognize the importance of three levels at which control may be exercised: learning management, cognitive processes and learning content" (p. 50). Furthermore, great emphasis has to be placed on the interdependence of these three levels, as effective learning management depends on the control of the cognitive processes which itself necessarily has consequences for learning self-management.

Control over learning management is regarded as an essential feature of self-directed learning. "It can be described in terms of the behaviors that learners employ in order to manage the planning, organization and evaluation of their learning" (Benson, 2001, p. 76). Indeed, it plays a key role in not only language learning, but also in learning how to learn. It can be argued that learners who become proficient in foreign languages usually manage to have some control over the whole direction of their learning. Thus, when it comes to implementing learner autonomy, it is crucially important to encourage learners to manage their own learning. Control over cognitive processes, on the other hand, is not only related to the ability to select appropriate learning strategies, but it is also concerned with particular mental processes. This has to do with attention, reflection, and meta-cognitive knowledge as the three major aspects of autonomy. As far as language learners are concerned, attention is taken into consideration as an integral element. This is because they need to exert cognitive responsibility for the linguistic input. Since "formal learning is the result of deliberate intention" (Little 1997, p. 94), learners need to have the ability to both reflect on the language itself and on the process of learning (Little, 1997). Indeed, "only experience that is reflected upon seriously will yield its full measure of learning, and reflection must in turn be followed by testing of hypotheses in order to obtain further experience" (Kohonen, 1992, p. 17). As a consequence, autonomous learners will be more capable of developing their own way of learning. Last but not least, control over content appears to be fundamental to autonomy. As a result of being capable of expressing personal meanings, autonomous learners are able to create personal learning contexts, which will enable them to be in charge of their own learning. Therefore, language authorities are required to create situational contexts in a way that promotes and rewards freedom in learning. 


\section{Independence and Interdependence}

Where discussing autonomy is concerned, using the word independence as its synonym might lead to some confusion. This is mainly because most of the time the terms autonomy and independence appear to be interchangeable. In this case, the opposite is the word dependence, which lays emphasis on strong reliance on teachers and teaching materials. However, "it can also be understood as the opposite of interdependence, which implies working together with teachers and other learners towards shared goals" (Benson, 2001, p. 14). Therefore, it may be argued that autonomy implies interdependence.

From a general point of view, independent learners are believed to able to work on their own without the aid of the teacher. Such a viewpoint is linked to not only the notion of self-access, but also to that of independent learning. A corollary of a reductionist view of autonomy as independence highlights that autonomous learners learn in isolation (Larsen-Freeman, 2001). However, it is argued that it can be misleading to equate autonomy with individualization and isolation, as "all learning is the product of interaction: learner autonomy does not arise spontaneously from within the learner but develops out of the learner's dialogue with the world to which he or she belongs" (Little, 1994, p. 431). It has its roots in interaction with others in social contexts. Indeed, by simply telling learners that they are independent, their capacity for autonomous learning will not be developed in formal contexts. Instead, "they must be helped to achieve autonomy by processes of interaction similar to those that underlie developmental and experiential learning" (Little, 1994, p. 435). This suggests that rather than being the product of independence, learner autonomy is the product of interdependence. Therefore, it can be argued that they both have to be taken into account as two interrelated aspects of autonomy and that autonomy needs to be explored in terms of its individual as well as social dimensions.

\section{Autonomy and Motivation}

There have been a number of justifications for promoting autonomy in both general education and language learning as a capacity for independent learning. As one of their underlying themes, there is the argument that autonomy results in learners entering into learning more purposefully. Indeed, "there is convincing evidence that people who take the initiative in learning (proactive learners) learn more things and learn better than those people who sit at the feet of teachers, passively waiting to be taught (reactive learners)" (Knowles, 1975, p. 14). Therefore, autonomy can lead to more efficient work with a higher level of motivation.

Mostly referred to as cognitive motivation, motivation is taken into account as willingness to learn with some purposeful effort. Thanks to taking responsibility for their own learning, autonomous learners benefit from a great deal of motivation enabling them to learn more effectively. This is because such learners believe they can succeed in learning provided that they concentrate their efforts on overtaking failure and using more efficient strategies. Indeed, those learners who pay particular attention to learning outcomes for their own sake rather than for rewards for their performance are highly motivated (Deci \& Ryan, 1985; Dweck, 1986). Thus, autonomy and motivation are closely linked through such concepts as learner independence, responsibility, and choice.

It is important to draw a distinction between intrinsic and extrinsic motivation. Intrinsically motivated learners are those who are interested in doing an activity for its own sake rather than for the sake of external pressure or even promised rewards. Extrinsic motivation, on the other hand, can be attributed to learning situations in which a task is performed due to some other reasons rather than a genuine interest in the task itself. It is argued that intrinsic motivation facilitates more effective learning, particularly when learners benefit from a measure of self-determination. This is because self-determination also results in intrinsic motivation, which can pave the way for both conceptual learning and creative thinking (Deci \& Ryan, 1985). Indeed, "self-determination is where the locus of causality for behavior is internal to the learner, and can be seen as related to the applied linguistic concept of autonomy in its sense of a capacity for and an attitude towards learning" (Dickinson, 1995, p. 169). Therefore, Dickinson (1995) believes that "the promotion of more effective learning is achieved both through learners being intrinsically motivated and through the learners operating in autonomy supporting and informational conditions" ( $p$. 169).

\section{Learner Autonomy and New Technology}

Where language learning is concerned, there is not a very straightforward relationship between autonomy and technology. It is often assumed that as a tool, the use of technology can benefit learners by facilitating the achievement of specific educational aims, one of which can be autonomy. However, it can be argued that as a set of learner internal affordances, autonomy itself can also act as an instrument to achieve some other educational aims (Reinders \& White, 2011). Therefore, when it comes to the impact of technology on autonomy, there seems to be 
some confusion between the process and product.

It is important to note that although autonomy is defined as "the learner's psychological relation to the process and content of learning - a capacity for detachment, critical reflection, decision-making, and independent action" (Little, 1991, p. 45), it is argued that it may appear to be multifaceted, as it can be differently interpreted by various people. It is often mistakenly considered to be independent, out-of-class learning where these are learners who have control over all aspects of their learning. From such a viewpoint, autonomous learners are believed to be intrinsically motivated, so much so that they are capable of learning outside the classroom on their own and without having to be supported by the teacher (Hafner \& Miller, 2011). However, it is also possible for learner autonomy to become a pedagogical objective by being developed in the structured learning environment of the classroom. In this case, there needs to be a deep focus on a student-centered approach where the teacher is still engaged in not only helping learners with their learning, but also in encouraging them to reflect on it (Schwienhorst, 2003). Therefore, a shift, in which technology can play an important role, can be gradually seen in the understanding of autonomy from a complex set of attitudes towards some certain abilities that pave the way for the navigation of different learning environments.

It should be mentioned that technology, and particularly the Internet as a source of information, can give learners the opportunity to have unlimited access to authentic materials in the target language. That is to say, it enables them to access a wide variety of resources for out-of-class learning which itself may encourage greater learner autonomy. Thanks to advances in technology, a broad range of opportunities have been created for self-directed learning (Gremmo \& Riley, 1995). Indeed, more and more learners are making good use of computer-assisted language learning (CALL) materials for their own purposes (O'Reilly, 2005). In the eyes of Ito et al. (2008, p. 2), "the affordances of new technologies make it possible for individuals to participate in the production and sharing of digital media and interact with a potentially global audience, in a way that is largely self-directed". Thus, as a result of being in control of their English on the Internet, learners can benefit from the opportunity to develop a strong sense of belonging to the wider English-speaking community across the world (Lam, 2000).

On the other hand, "the new technologies offer the potential for autonomous language learning, especially in the context of globalized online spaces such as Flickr, YouTube, and FanFiction.net, where it is possible to share and discuss a range of digital artifacts "(Benson \& Chik, 2010, p. 63). More recently, new mobile technologies such as smart phones and tablet computers have not only led to a greater richness of resources readily available to language learners (Murray, 2005), but they also double as a platform for out-of-school contexts (Kukulska-Hulme \& Traxler, 2005). Therefore, as a result of enhanced opportunities for interaction and support for learning outside the classroom, it may be hypothesized that technology can link affordances in the environment to the development of greater learner autonomy. However, it cannot be not enough by itself.

Although learners may be used to engaging with technology for their leisure and social pursuits, they may find learning to use technology for learning purposes more difficult. It is argued that proper guidance plays a crucial role in fostering learner autonomy (Hafner \& Candlin, 2007; Schwienhorst, 2007). In the absence of appropriate guidance and feedback, having unlimited access to authentic materials might have detrimental effects and even make it more challenging for learners to develop their degree of autonomy (Murray, 1999). Simply stated, inappropriate pedagogical purpose as well as poor implementation might cause the benefits of technology to fade. For instance, online dictionaries might discourage learners from learning new vocabulary items off by heart. Consequently, technology might give a false sense of development to learners (Gee, 2003). Indeed, in order for an approach to technology to be developed in a way that fosters learner autonomy, it is essential to explore the interrelation between pedagogy and technology. Therefore, it is important to not only use a student-centered approach, but also to pay particular attention to the affordances of certain technological tools for language learners to become more autonomous (Schwienhorst, 2007).

\section{Conclusion}

With the shift towards more communicative and learner-centered approaches to teaching, particular attention has been paid to the promotion of autonomy as a capacity for independent learning, and a significant number of justifications have been proposed for fostering learner autonomy in language learning. To do so, there is a need for consciousness of the learning process so that learners can become aware of what they have already achieved and further reflect on it. Responsibility and control over content have been highlighted as the core aspects of learner autonomy. Autonomous learners take responsibility for their own learning by devising effective learning strategies. This deals with attention, reflection, and meta-cognitive knowledge as the three major aspects of autonomy. In addition, learner autonomy has its roots in interaction with others in social contexts. Since independence and 
interdependence are taken into account as two interrelated aspects of autonomy, there is a need for it to be explored in terms of both individual and social dimensions. Furthermore, autonomy and motivation are closely linked through such concepts as learner independence, responsibility, and choice. As a result of being in charge of their own learning, autonomous learners will benefit from a high level of motivation and therefore learn more efficiently. Indeed, intrinsic motivation facilitates more effective learning by paving the way for not only conceptual learning, but also for creative thinking. A gradual shift can be noticed in the understanding of autonomy from a complex set of attitudes towards certain abilities that facilitate the navigation of different learning environments. By providing learners with the opportunity to have unlimited access to authentic materials in the target language, technology - particularly the Internet as a source of information - can play an important role in such a shift. It enables learners to access a wide range of resources for out-of-class learning, which may encourage greater learner autonomy. Although technology seems to have the potential to create opportunities for the promotion of autonomous learning, it is not enough by itself. It should be mentioned that proper guidance plays a major role in fostering learner autonomy, so much so that in order for an approach to technology to be developed in a way that promotes learner autonomy, it is necessary to explore the interrelation between pedagogy and technology. Therefore, it is important to not only use a student-centered approach, but also to pay particular attention to the affordances of certain technological tools for language learners to become more autonomous.

\section{References}

Benson, P. (1997). The philosophy and politics of learner autonomy. In P. Benson \& P. Voller (Eds.), Autonomy and independence in language learning (pp. 18-34). London: Longman.

Benson, P. (2001). Teaching and researching autonomy in language learning. Harlow: Pearson Education Limited.

Benson, P. (2006). Autonomy in language teaching and learning. Language Teaching, 40, 21-40. https://doi.org/10.1017/S0261444806003958

Benson, P., \& Chik, A. (2010). New literacies and autonomy in foreign language learning. In M. J. Luzon, M. N. Ruiz-Madrid, and M. L. Villanueva (Eds.), Digital genres, new literacies and autonomy in language learning (pp. 63-80). Newcastle: Cambridge Scholars.

Brenkert, G. (1991). Political Freedom. London: Routledge.

Brown, H. D. (2000). Principles of language learning and teaching (4th ed.). New York: Addison Wesley Longman.

Cotterall, S. (1995). Readiness for autonomy: Investigating learner beliefs. System, 23(2), 195-206. https://doi.org/10.1016/0346-251X(95)00008-8

Dam, L. (1995). Learner Autonomy 3: From Theory to Classroom Practice. Dublin: Authentik.

Deci, E. L., \& Ryan, R. M. (1985). Intrinsic motivation and self-determination in human behavior. New York: Plenum Press. https://doi.org/10.1007/978-1-4899-2271-7

Dickinson, L. (1987). Self-instruction in language learning. Cambridge: Cambridge University Press.

Dickinson, L. (1995). Autonomy and motivation: A literature review. System, 23(2), 165-174. https://doi.org/10.1016/0346-251X(95)00005-5

Dweck, C. S. (1986). Motivational processes affecting learning. American Psychologist, 41(10), 1040-1048. https://doi.org/10.1037/0003-066X.41.10.1040

Ellis, G., \& Sinclair, B. (1989). Learning to Learn English: a course in learner training. Cambridge: Cambridge University Press.

Gee, J. P. (2003). What video games have to teach us about learning and literacy. Basingstoke: Palgrave Macmillan. https://doi.org/10.1145/950566.950595

Gremmo, M. J., \& Riley, P. (1995). Autonomy, self-direction and self-access in language teaching and learning: The history of an idea. System, 23(2), 151-164. https://doi.org/10.1016/0346-251X(95)00002-2

Hafner, C. A., \& Candlin, C. N. (2007). Corpus tools as an affordance to learning in professional legal education. Journal of English for Academic Purposes, 6(4), 303-318. https://doi.org/10.1016/j.jeap.2007.09.005

Hafner, C. A., \& Miller, L. (2011). Fostering Learner Autonomy in English for Science: A Collaborative Digital Video Project in a Technological Learning Environment. Language Learning \& Technology, 15(3), 68-86.

Halliday, M. A. K. (1975). Learning how to mean: Explorations in the development of language. London: Edward Arnold. https://doi.org/10.1016/B978-0-12-443701-2.50025-1 
Holec, H. (1981). Autonomy in foreign language learning. Oxford: Pergamon.

Ito, M., Horst, H., Bittanti, M., boyd, D. M., Herr-Stephenson, B., Lange, P. G., ... Robinson, L. (2008). Living and learning with new media: Summary of findings from the Digital Youth Project. Chicago, IL: The John D. and Catherine T. MacArthur Foundation. https://doi.org/10.7551/mitpress/8519.001.0001

Knowles, M. S. (1975). Self Directed Learning: A Guide for Learners and Teachers. Chicago: Association Press.

Kohonen, V. (1992). Experiential language learning: second language learning as cooperative learner education. In D. Nunan (Eds.). (1992a) Collaborative Language Learning and Teaching. Cambridge: Cambridge University Press, 37-56.

Kohonen, V. (2001). Developing the European language portfolio as a pedagogical instrument for advancing student autonomy. All Together Now, 20-44.

Kukulska-Hulme, A., \& Traxler, J. (2005). Mobile learning: a handbook for educators and trainers. London, UK: Routledge.

Lam, W. S. E. (2000). L2 literacy and the design of the self: A case study of a teenager writing on the Internet. TESOL quarterly, 34(3), 457-482. https://doi.org/10.2307/3587739

Larsen-Freeman, D. (2001). Individual cognitive/ affective learner contributions and differential success in second language acquisition. In M. P. Breen (ed.), Learner contributions to language learning: New Directions in Research, (pp. 12-24). New York: Longman.

Larsen-Freeman, D. (2001). Individual cognitive/affective learner contributions and differential success in second language acquisition. Learner contributions to language learning, 12-24.

Little, D. (1991). Learner Autonomy 1: Definitions, Issues and Problems, Dublin: Authentik.

Little, D. (1994). Learner autonomy: A theoretical construct and its practical application. Die Neueren Sprachen, 93(5), 430-442.

Little, D. (1997). Language awareness and the autonomous language learner. Language Awareness, 6(2/3), 93-104. https://doi.org/10.1080/09658416.1997.9959920

Little, D., \& Dam, L. (1989). Learner autonomy: drawing together the threads of self-assessment, goal-setting and reflection: Authentik.

Littlejohn, A. (1985). Learner choice in language study. English Language Teaching Journal, 39(4), $253-261$. https://doi.org/10.1093/elt/39.4.253

Littlewood, W. (1996). Autonomy: an anatomy and a framework. System, 24(4), 427-435. https://doi.org/10.1016/S0346-251X(96)00039-5

Murray, D. E. (2005). Technologies for second language literacy. Annual Review of Applied Linguistics, 25, $188-201$. https://doi.org/10.1017/S0267190505000103

Murray, G. L. (1999). Autonomy and language learning in a simulated environment. System, 27, $295-308$. https://doi.org/10.1016/S0346-251X(99)00026-3

Nunan, D. (1988). The learner-centered curriculum. Cambridge: Cambridge University Press. https://doi.org/10.1017/CBO9781139524506

Nunan, D. (1992). Collaborative Language Learning and Teaching. Cambridge: Cambridge University Press.

Nunan, D. (1997). Designing and adapting materials to encourage learner autonomy. In Benson, P., \& Voller, P. (eds) Autonomy \& Independence in Language Learning. Harlow: Addison Wesley Longman Ltd., 192-203.

O'Reilly, T. (2005). What Is Web 2.0? Design patterns and business models for the next generation. Retrieved July 11, 2019 from http://oreilly.com/web2/archive/what-is-web-20.html

Oxford, R. L. (1990). Language Learning Strategies: What Every Teacher Should Know. Boston, MA: Heinle \& Heinle.

Oxford, R. L. (2003). Toward a more systematic model of L2 learner autonomy. In D. Palfreyman \& R. C. Smith (Eds.), Learner autonomy across cultures: Language education perspectives (pp. 75-91). Basingstoke: Palgrave Macmillan. https://doi.org/10.1057/9780230504684_5

Pennycook, A. (1997). Cultural alternatives and autonomy. In P. Benson, and P. Voller. Autonomy and Independence 
in Language Learning (pp. 35-53). Harlow: Longman.

Raz, J. (1986). The Morality of Freedom. Oxford: Clarendon Press.

Reinders, H., \& White, C. (2011). Learner autonomy and new learning environments. Language Learning \& Technology, 15(3), 1-3. http://lit.msu.edu/issues/october2011/commentary.pdf

Schwienhorst, K. (2003). Learner autonomy and tandem learning: putting principles into practice in synchronous and asynchronous telecommunication environments. Computer Assisted Language Learning, 16(5), 427-443. https://doi.org/10.1076/call.16.5.427.29484

Schwienhorst, K. (2007). Learner autonomy and CALL environments. London: Routledge.

Sinclair, B. (1996). Materials design for the promotion of learner autonomy: how explicit is "explicit"? In Pemberton, R., Li, E, Or, W \& Pierson, H. (eds.) Taking Control: Autonomy in Language Learning, (pp 149-165). Hong Kong: Hong Kong University Press.

Sinclair, B. (2000). Learner Autonomy and its Development in the Teaching of English to Speakers of Other Languages (TESOL). Ph.D Thesis, University of Nottingham.

Sinclair, B. (2000). Learner autonomy: The next phase? In B. Sinclair, I. McGrath \& T. Lamb (eds.), Learner autonomy, teacher autonomy: Future directions (pp. 4-14). Harlow: Longman.

Skehan, P. (1989). Individual Differences in Second Language Learning. London: Edward Arnold.

Vestheim, G. (2007). Theoretical reflections. International Journal of Cultural Policy, 13(2), $217-236$. https://doi.org/10.1080/10286630701342907

Vestheim, G. (2009). The autonomy of culture and the arts-from the Early Bourgeois Era to Late modern 'Runaway World'. What about cultural policy, 53-31.

Wenden, A. L. (1991). Learner Strategies for Learner Autonomy. Hemel Hempstead: Prentice Hall.

Williams, M., \& Burden, R. L. (1997). Psychology for language teachers: A social constructivist approach. Cambridge: Cambridge University Press.

Willing, K. (1988). Learning Styles in Adult Migrant Education. Australia: NCRC Research Series.

Young, R. (1986). Personal Autonomy: Beyond Negative and Positive Liberty. London: Croom Helm. 